\title{
The Effect of Vitamin D3 and its Relationship with the Level of White Blood Cells in Women Spontaneous Miscarriage Undergoing Intracytoplasmic Sperm Injection (ICSI) Technique
}

\author{
Dhirgam F. Hassan Al-Shimerty ${ }^{1}$, Alaauldeen S.M. AL-Sallami ${ }^{2}$ \\ ${ }^{1}$ Associate Professor, ${ }^{2}$ Professor, Department of Biology, Faculty of Sciences/Kufa University, \\ AL-Najaf Province/Iraq
}

\begin{abstract}
Women were studied undergoing ICSI for 84 who suffer non-pregnancy at the Fertility Center, Al-Sadr Medical Hospital in Najaf Governorate, Period between January 2019 and March 2020. WBC, Vitamin D3 and $\beta$-hCG were measured, The pregnant women was divided into (Pregnancy Group, and spontaneous miscarriage) and then demonstrate the immunological effect on pregnancy of women after ICSI technique.

Current results study showed a significant increase $(p<0.05)$ in hormone level $\beta$-hCG is evidence of the presence of high success rates for pregnancy in women who performed operations IVF, where the success rate at the beginning of the matter reached $61.9 \%$, after which it decreased to $33.3 \%$ after the first three months due to the occurrence of spontaneous miscarriage of pregnant women due to various immunological and physiological reasons, a positive correlation between the level of $\beta$-hCG and other parameters in the study (Vitamin D3 -WBC).Also The current results showed a significant decrease in a groups (pregnancy failure) and the group (spontaneous miscarriage) compared with the control group (continued pregnancy) in relation to the level of vitamin D3 Also, The current results showed a significant increase in (pregnancy failure) and (spontaneous miscarriage) compared with control groups (continuation of pregnancy) in relation WBC numbers, and the present study founds a negative relationship between the level of vitamin D3 and WBC.
\end{abstract}

Keywords: Miscarriage, ICSI technique,vitamin D3, white blood cells.

\section{Introduction}

Infertility is a widespread disease worldwide and it means "the inability of the spouses to achieve pregnancy within one year of marriage" and the estimated rate of infertility in the world is around $15-20 \%{ }^{1}$. In vitro

Corresponding Author:

\section{Dhirgam F. Hassan Al-Shimerty}

Associate Professor, Department of Biology, Faculty of Sciences/Kufa University, AL-Najaf Province/Iraq e-mail: hmk20001999@sci.utq.edu.iq

Mobile No.: 07801738839 fertilization, intracytoplasmic sperm injection (ICSI), and intrauterine insemination (IUI) be are the main method of assisted reproductive technology (ART). Found a several Various studies in recent years have indicated that occur risk factor for implantation failure of women after ICSI which may be immunological parameters or biochemical parameters may be affected on In ICSI results ${ }^{2,3}$.

Measuring hematological parameters is one of the factors that affect pregnancy and its effect because it is a reliable indicator, and it is a simple, fast, and effective test since increasing the number of leukocytes in the event that infection is not detected that leads to important damage ${ }^{4,5}$. Several studies have reported that pregnancy 
in sometimes accompanied by leukocytosis, but complete chain changes to the different types of cells responsible for this observed leukocytosis number has not been clearly identified in all studies related to pregnancy ${ }^{6,7}$. White blood cells (WBCs) are an important part of the immune system in a pregnant woman's body as high white blood cells for some reason during pregnancy may lead to spontaneous abortion due to increase infection in the urinary tract or immune system problems ${ }^{8,9}$.

The most important source of vitamin $\mathrm{D}$ is the skin's synthesis of vitamin B from ultraviolet B, and any process that reduces the entry of ultraviolet $B$ photons into the skin will reduce the production of cholecalciferol (vitamin D-3). Melanin absorbs skin pigment with UVB photons and can reduce vitamin D-3 synthesis by\&gt; $90 \%{ }^{10,11}$.Vitamin $\mathrm{D}$ also worsens in the winter months (November to March), when latitudes reach above $37{ }^{\circ} \mathrm{C}$ ultraviolet $\mathrm{B}$ radiation decreases to Earth and little or no vitamin D can be synthesized in the skin, as vitamin D plays a prominent role in Calcium and phosphorous stabilization, and its deficiency has been shown to increase the risk of osteoporosis, fractures, and muscle weakness ${ }^{12,13}$. Also, female reproduction is a one of the areas in which the role of vitamin D has not been extensively examined. However, early evidence from basic research strongly indicates the potential role of vitamin D in human reproduction, especially women $^{14,15}$. It turns out that the effects of a lack of Vitamin D3 on pregnant women expose them to the problems of spontaneous abortion or premature birth due to failure of the placenta function, pre-eclampsia, gestational diabetes, bacterial vaginitis, and poor growth and development of the fetus and childhood, as preserving must be maintained at sufficient levels throughout the period Pregnancy ${ }^{16,17}$. The aim of this study was to study the relationship of white blood cell count in pregnancy and its relationship to vitamin D3 for aborted women under ICSI.

\section{Materials and Method}

This is this study in the laboratories of the Department of Biology, College of Science, University of Kufa, and in the Laboratory of Fertility Center in Sadr City Medical City in Najaf Governorate/Najaf Health Directorate/Ministry of Health/Iraq. Venous blood samples were taken from women at three times, the first stage 14 days after the right, the second stage after spontaneous abortion in the third trimester while the third stage for women who are pregnant continuously and using a needle and syringes is used once from each patient and observer. The $\beta$-hCG level and the vitamin D3 level were measured using the ELISA method and the white blood cell count was measured by the GENEX blood analyzer. The research was approved by the ethics review committees of Al-Sadr Education City and the College of Sciences at Kufa University.

Statistical Analysis: The popular statistical system (Graph Pad prism ver. 5) was adopted, and a one-way analysis of variance table - Anova method (by Tukey's multi-comparative test) was used to compare the groups divided into the measured parameters. The results are expressed as (Mean \pm Stander Error). Correlation coefficients were calculated to estimate the correlation between tags and parameters. Descriptive statistics and correlation coefficients were performed using mega stat (V10.12 version) for excel 2010 (18).

\section{Results}

Results of $\beta$ - Human chorionic gonadotropin hormone test: In this test showed found significant difference $(p<0.05)$ between pregnant women which was $52(4.24 \pm 0.25)$ and non- pregnant women (Implantation Failure) $(2.56 \pm 0.10)$ which was 32 from women which undergoing intracytoplasmic sperm injection technique as shown in figure (1). 


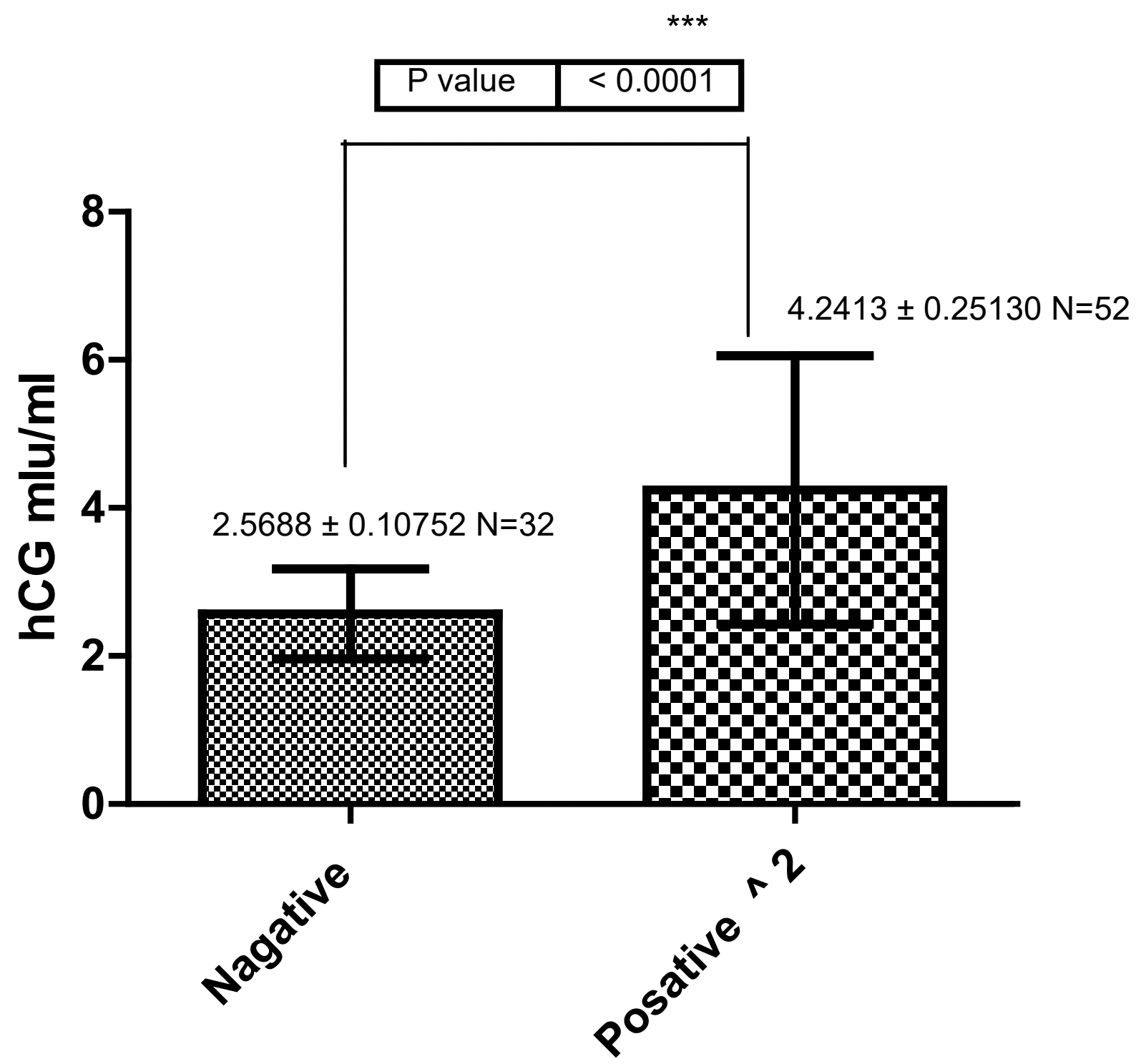

(*) mean indicates significant $(\mathrm{p}<0.05)$.

Figure (1): Result $\beta$-Human chorionic gonadotropin hormone test which differ between pregnant women which was 52 and non- pregnant women (Implantation Failure) which was 32 from women which undergoing intracytoplasmic sperm injection technique .

\section{Results of White Blood Cell Count}

In this test showed found significant difference $(p<0.05)$ between Continuous pregnant women (control group) which was 28 women and non- pregnant women groups which was 56 from women which undergoing intracytoplasmic sperm injection technique (Implantation Failure (32) and found non significant difference with spontaneous miscarriage (24)) as shown in figure (2). 


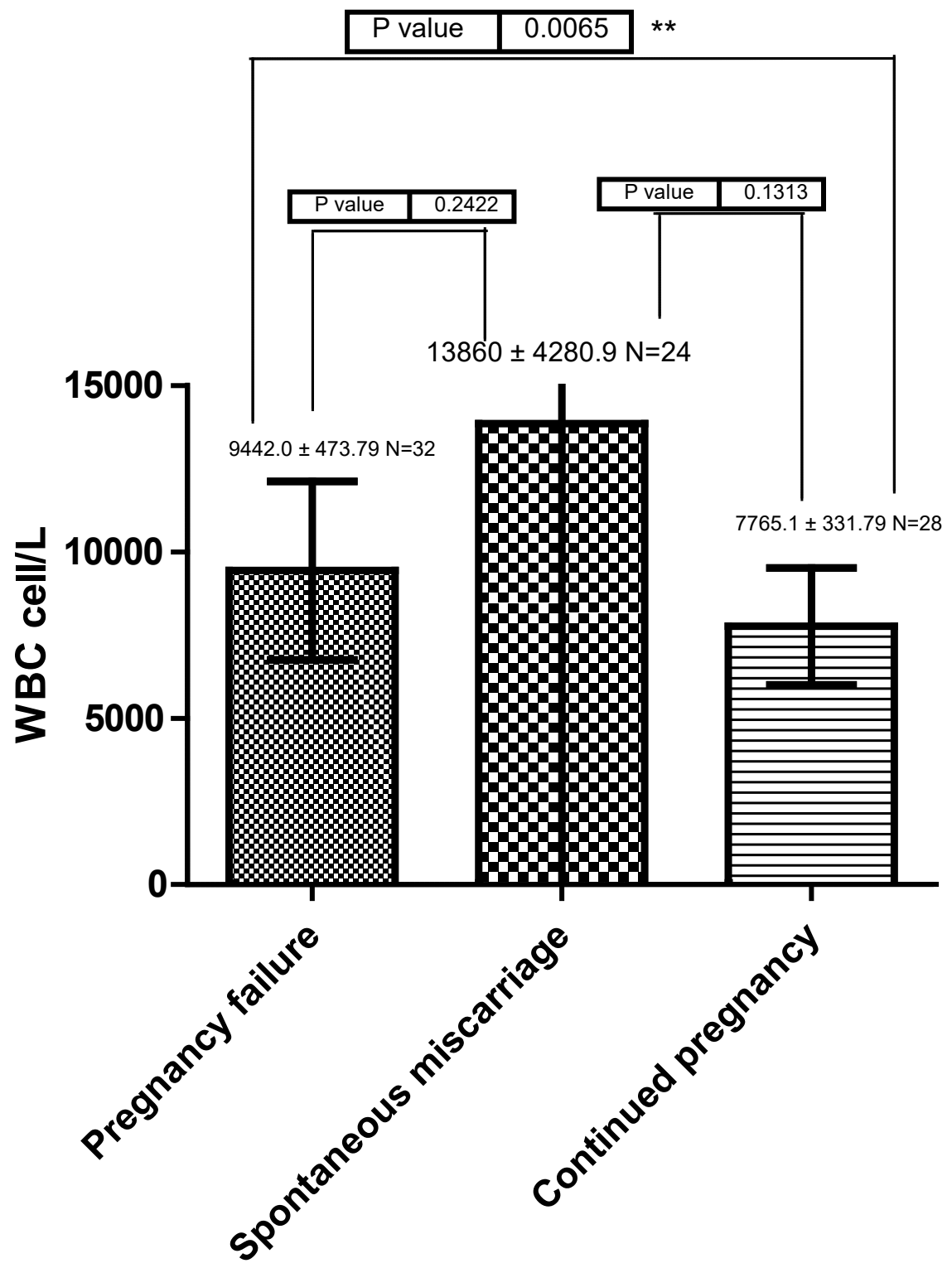

(*) mean indicates significant $(\mathrm{p}<0.05)$.

Figure (2): Results of White blood cell Count test which differ between Continuous pregnant women (control group) which was 28 women and non- pregnant women groups which was 56 from women which undergoing intracytoplasmic sperm injection technique (Implantation Failure (32) and spontaneous miscarriage (24)).

Results of Vitamin D3 test: In this test showed found significant difference $(\mathrm{p}<0.05)$ between Continuous pregnant women (control group) which was 28 women and non- pregnant women groups which was
56 from women which undergoing intracytoplasmic sperm injection technique (Implantation Failure (32) and spontaneous miscarriage (24)) as shown in figure (3). 


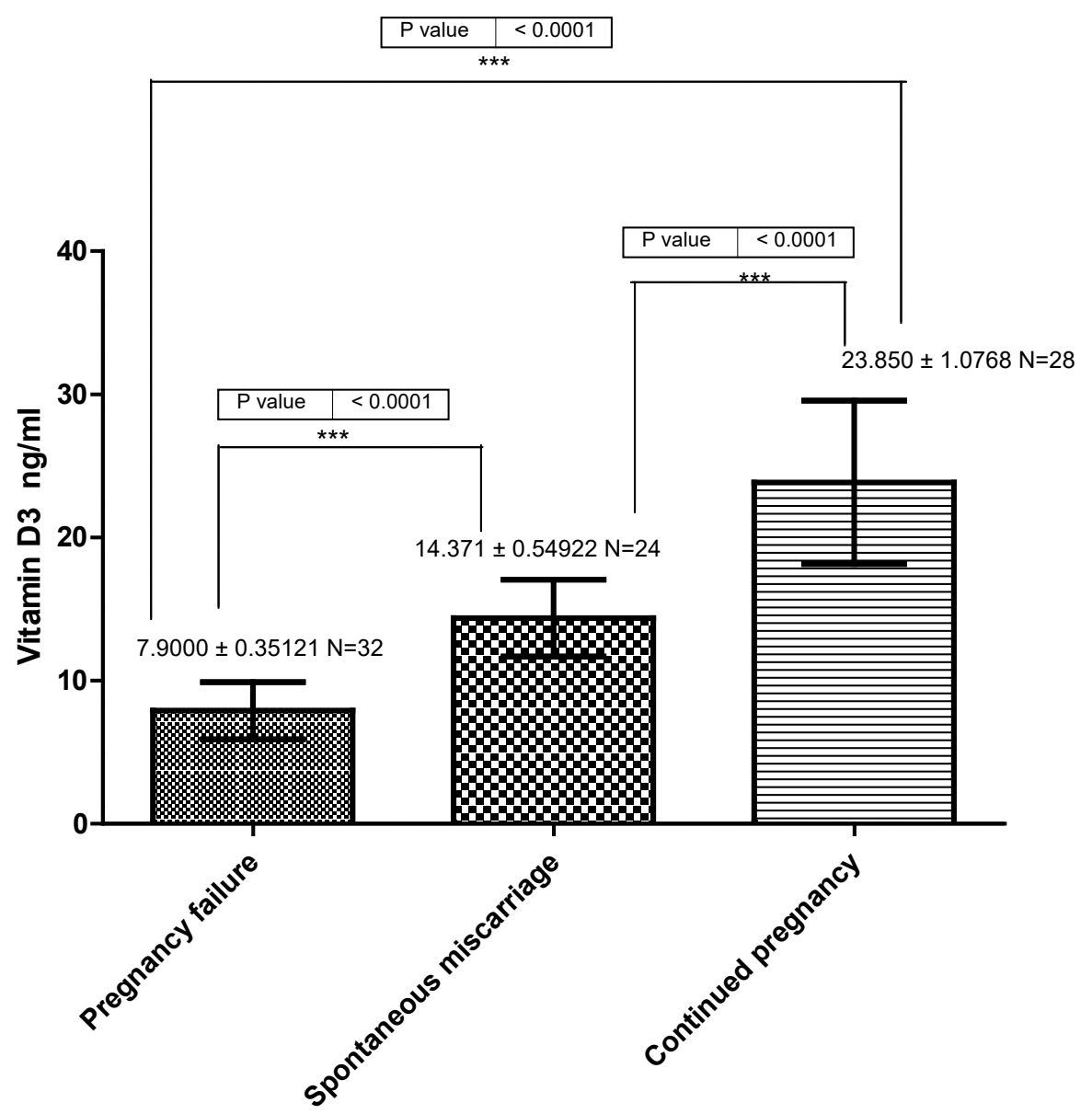

(*) mean indicates significant $(\mathrm{p}<0.05)$.

Figure (3): Results of Vitamin D3 test which differ between Continuous pregnant women (control group) which was 28 women and non- pregnant women groups which was 56 from women which undergoing intracytoplasmic sperm injection technique (Implantation Failure (32) and spontaneous miscarriage (24)).

The correlation between Vitamin D3 with White blood cell count: The study showed the presence of a negative correlation between Vitamin D3 with White blood cell count Figure (4).

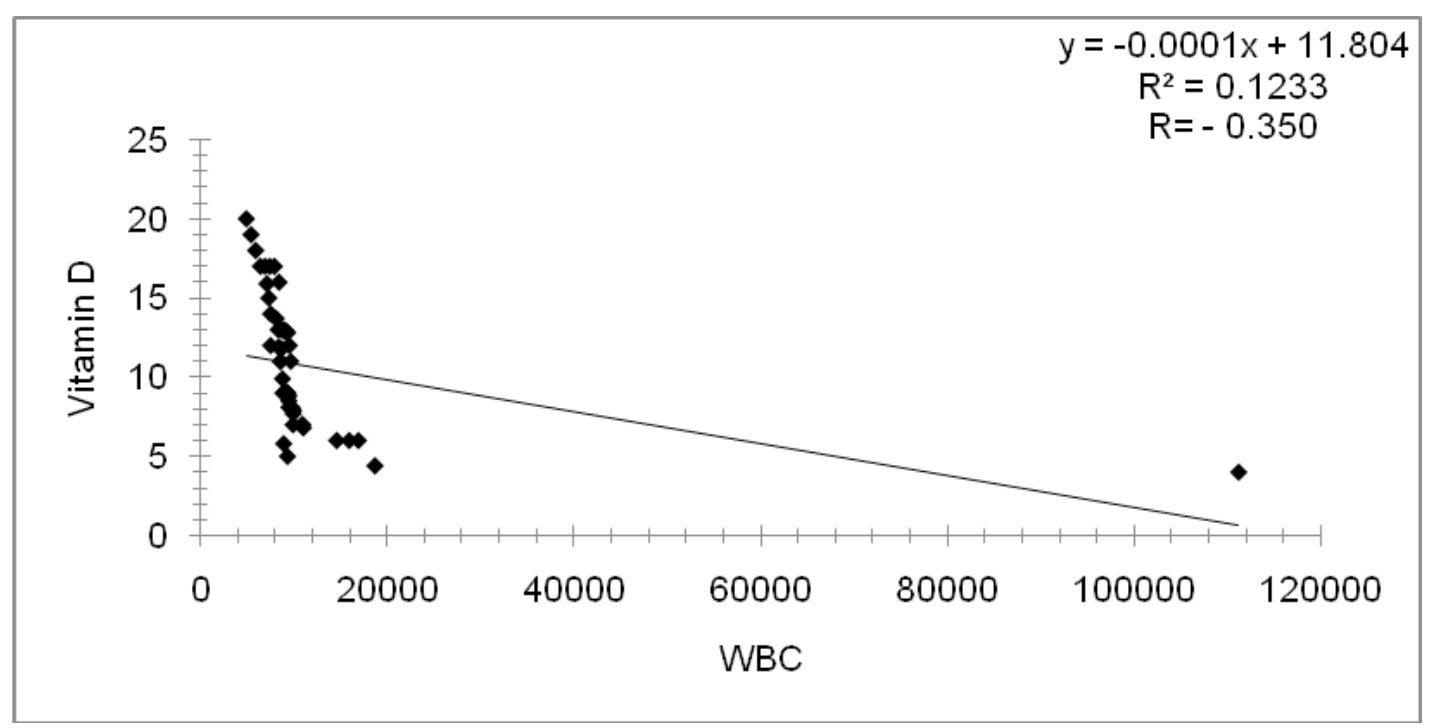

Figure (4): The correlation between Vitamin D3 with Wbc. 


\section{Discussion}

The results of the current research showed a significant increase in the level of significance $(p<0.05)$ in the level of the $\beta$ - Human chorionic gonadotropin hormone, and the reason for this is that this hormone is evidence of the presence of pregnancy in women who underwent ICSI operations may be because it is excreted mainly from the placenta during the formation of the fetus and this study is consistent with what reached ${ }^{19}$.in this regard and that the increase in the level of this hormone is evidence of high success rates of pregnancy for women who conducted ICSI operations, where the success rate initially reached $61.9 \%$, after which it decreased to $33.3 \%$ after the first three months due to the occurrence of spontaneous abortions for women. Pregnant women for various immunological and physiological reasons, as this study indicated, and these results are consistent with what was reached ${ }^{20,21,22}$.

The results of the current study also showed a significant difference at the level of significance $(p<0.05)$ between the groups (pregnancy failure - spontaneous abortion) compared to the control group (continuous pregnancy) in vitamin D3 level. Also, the current study showed a significant difference in the vitamin D3 level between the pregnancy group, and spontaneous abortion group, and perhaps the reason for this is that vitamin D3 has a major role in miscarriage in women because the lack of vitamin D3 leads to the accumulation of white blood cells in Capillaries in the uterine of women, which leads to a decrease in blood flow to the uterine layers which leads to a weakening of the uterine layer Which leads to uterine weakness in women, which leads to pregnancy failure or spontaneous abortion, and the main reason for this vitamin deficiency is that most women are not exposed to direct sunlight, as studies have shown that the body gets $90 \%$ of vitamin D3 through exposure to sunlight. These results are consistent with what has been achieved ${ }^{23,24}$. Where they said in their study that it is clear that abortions occur in pregnant women who have a low level of vitamin D3 where there was an acute shortage of vitamin D3 in the sunny climate, such as Britain, which leads to many of these problems. Dr. Sonny Mo Ford of the National Institute of Ioni Kennedy Shriver said his findings that vitamin D3 plays an important role in protecting pregnancy in women who are undergoing a program in vitro fertilization meanings reproduction especially intracytoplasmic sperm injection. The results of the current research showed a significant increase at the level of significance $(\mathrm{p}<0.05)$ between the groups (pregnancy failure) and the group (spontaneous miscarriage) compared with the control group (continuing pregnancy) with respect to white blood cells count while The differences were significant between the (pregnancy failure) group and the (spontaneous miscarriage) group, and this study is consistent with the findings of ${ }^{25,26}$. And this result may be explained that is the reason for this is that pregnant women have a lowed white blood cells count level compared to abort women This may be because white blood cells count is evidence of the presence of infections in the genital and urinary tract as a result of the abortion process, where these results are consistent with what was reached 27,28 . Where he explained the presence of a significant increase in white blood cells women abortifacients and pregnancy after a period when the failure of vaccination compared to non- spontaneous miscarriage women.

The current study also showed a negative correlation between the level of white blood cells, and vitamine D3 level perhaps the reason for this is that vitamin D3 has a major role in miscarriage in women because the lack of vitamin D3 leads to the accumulation of white blood cells in Capillaries in the utrine of women, and increase in the white blood cells which leads to a decrease in blood flow to the uterine layers which leads to a weakening of the uterine layer Which leads to uterine weakness in women, which leads to pregnancy failure or spontaneous abortion. This study is consistent with the findings of 29,30 , where it was explained that a lack of vitamin D3 in pregnant women leads to an increase in the level of white blood cells as an immune reaction and thus leads to miscarriage as a result of the accumulation of these cells in the blood vessels, which leads to a lack of flow Blood to the womb and weak endometrium,

\section{Conclusions}

From the result of this study showed a positive effect between a deficiency of vitamin D3 and the chances of infection of pregnancy in women who underwent ICSI.

Ethical Clearance: Guidelines of the Ethical Committee of the human and animal Research at the university of kufa were followed, which conform to the recommendations on confidentiality and privacy of human samples were followed throughly.

Conflict of Interests: The authors declared they have no competing interests. 
Funding: This project was privately and equally funded by all authors in the manuscript.

Acknowledgements: The authors in this research would like to thank all the staff at the faculty of medicine for their assistance and valuable contribution to this project.

\section{References}

1. Poongothai S, Pradeepa R, Ganesan A, Mohan $\mathrm{V}$. Prevalence of depression in a large urban south Indian population - The Chennai urban rural epidemiology study (cures - 70). PLoS One. 2009;4(9).

2. Vitorino RL, Grinsztejn BG, de Andrade CA, Hökerberg YH, de Souza CT, Friedman RK, Passos SR. Systematic review of the effectiveness and safety of assisted reproduction techniques in couples serodiscordant for human immunodeficiency virus where the man is positive. Fertility and sterility. 2011 Apr 1;95(5):1684-90.

3. Bungum M, Humaidan P, Spano M, Jepson K, Bungum L, Giwercman A. The predictive value of sperm chromatin structure assay (SCSA) parameters for the outcome of intrauterine insemination, IVF and ICSI. Human Reproduction. 2004 Jun 1;19(6):1401-8.

4. Zhu $\mathrm{X}, \mathrm{Fu} \mathrm{Y}$. Use of dydrogesterone during controlled ovarian hyperstimulation in normal ovulatory women treated for in vitro fertilization or intracytoplasmic sperm injection treatments. Fertility and Sterility. 2017 Sep 1;108(3):e226-7.

5. Glenn A, Armstrong CE. Physiology of red and white blood cells. Anaesthesia \& Intensive Care Medicine. 2019 Feb 21.

6. Obebe OO, Falohun OO, Olajuyigbe OO, Lawani MA, Ajayi OA. Impact of asymptomatic Plasmodium falciparum on haematological parameters of pregnant women at first antenatal visit in South-western Nigeria. Tanzania Journal of Health Research. 2018;20(2).

7. Adesina OA, Fasola F, Adekanbi O, Ogunbosi B, Akinyemi J, Kuti MA, Michael O, Fayemiwo A, Awolude O, Adewole I. Burden of cytopaenias among HIV positive pregnant women at the University College Hospital, Ibadan. Annals of Ibadan Postgraduate Medicine. 2018;16(2):99-108.

8. Maglaviceanu CF, Bechir ES, Tuculina MJ, Daguci C, Dascalu IT, Daguci L, Nicola A, Popescu MS,
Bataiosu M. The Role of the Leucocytosis Parameter in the Occurrence of Pregnancy Complications in Women with Periodontal Disease. REVISTA DE CHIMIE. 2019 Nov 1;70(11):3967-70.

9. Kyakulaga P, Mwambi B, Atuhairwe C, Taremwa IM. Haematological Parameters of Pregnant Women Attending Antenatal Care at Nakaseke Hospital, Central Uganda.

10. AL-Msaid HL, AL-Sallami AS. Study the Level of Cytokine in Unexplained and Idiopathic Infertile Men. Journal of Pharmaceutical Sciences and Research. 2018 Apr 1;10(4):808-11.

11. Hirsch AL. Industrial aspects of vitamin D. InVitamin D 2011 Jan 1 (pp. 73-93). Academic Press.

12. Hartl C, Obermeier V, Gerdes LA, Brügel M, von Kries R, Kümpfel T. Seasonal variations of $25-\mathrm{OH}$ vitamin D serum levels are associated with clinical disease activity in multiple sclerosis patients. Journal of the neurological sciences. 2017 Apr 15;375:160-4.

13. Mitchell BL, Zhu G, Medland SE, Renteria ME, Eyles DW, Grasby KL, McGrath JJ, Martin NG. Half the Genetic Variance in Vitamin D Concentration is Shared with Skin Colour and Sun Exposure Genes. Behavior genetics. 2019 Jul 15;49(4):386-98.

14. Amini S, Jafarirad S, Amani R. Postpartum depression and vitamin D: A systematic review. Critical reviews in food science and nutrition. 2019 May 15;59(9):1514-20.

15. Cermisoni GC, Alteri A, Corti L, Rabellotti E, Papaleo E, Viganò P, Sanchez AM. Vitamin D and endometrium: A systematic review of a neglected area of research. International journal of molecular sciences. 2018 Aug;19(8):2320.

16. Al-Msaid HL, AL-Sallami AS. Study of Catsper1 Protein Levels in Unexplained and Idiopathic Infertile Men. International Journal of Pharmaceutical Quality Assurance. 2018 Jan 21;9(02):195-8.

17. Holick MF. The vitamin D deficiency pandemic: approaches for diagnosis, treatment and prevention. Reviews in Endocrine and Metabolic Disorders. 2017 Jun 1;18(2):153-65.

18. Motulsky HJ. Prism 4 statistics guide - statistical analyses for laboratory and clinical researchers. GraphPad Software Inc., San Diego, CA. 2003:122- 
6.

19. Gold RS, Azem F, Yovel I, Wagman I, Amit A, Lessing JB. Does ICSI affect early serum $\beta$-HCG in pregnancies achieved after IVF? Human reproduction. 2000 Jun 1;15(6):1221-4.

20. Y1lmaz N, Ceran MU, Ugurlu EN, Gülerman HC, EnginUstun Y. GnRH agonist versus HCG triggering in different IVF/ICSI cycles of same patients: a retrospective study. Journal of Obstetrics and Gynaecology. 2019 Nov 29:1-6.

21. Harun R, Ruban L, Matin M, Draper J, Jenkins NM, Liew GC, Andrews PW, Li TC, Laird SM, Moore HD. Cytotrophoblast stem cell lines derived from human embryonic stem cells and their capacity to mimic invasive

22. implantation events. Human reproduction. 2006 Jun 1;21(6):1349-58.

23. Sandi-Monroy NL, Musanovic S, Zhu D, Szabó Z, Vogl A, Reeka N, Eibner K, Bundschu K, Gagsteiger F. Use of dimethylxanthine theophylline (SpermMobil@) does not affect clinical, obstetric or perinatal outcomes. Archives of gynecology and obstetrics. 2019 Nov 1;300(5):1435-43.

24. Dimitris MC, PerumalN, Craig-Barnes HA, Leadley M, Mahmud AA, Baqui AH, Roth DE. Effect of weekly high-dose vitamin D3 supplementation on serum cholecalciferol concentrations in pregnant women. The Journal of steroid biochemistry and molecular biology. 2016 Apr 1;158:76-81.

25. Sharef AA, Hussien SS, Noori FM. Vitamin D3 deficiency and early pregnancy loss. Middle East Journal of Family Medicine. 2020 Jan 1;7(10):76.

26. Funasaka N, Yoshioka $M$, Ueda $K$, Koga $H$, Yanagisawa M, Koga S, Tokutake K. Long-term monitoring of circulating progesterone and its relationship to peripheral white blood cells in female false killer whales Pseudorca crassidens. Journal of Veterinary Medical Science. 2018:180075.

27. Fraichard C, Bonnet F, Garnier A, Hébert-Schuster M, Bouzerara A, Gerbaud P, Ferecatu I, Fournier T, Hernandez I, Trabado S, Guibourdenche J. Placental production of progestins is fully effective in villous cytotrophoblasts and increases with the syncytiotrophoblast formation. Molecular and cellular endocrinology. 2020 Jan 1;499:110586.

28. Bas FY, Tola EN, Sak S, Cankaya BA. The role of complete blood inflammation markers in the prediction of spontaneous abortion. Pakistan journal of medical sciences. 2018 Nov;34(6):1381.

29. Wang J, Liu C, Que W, Fujino M, Tong G, Yan H, Li XK. Immunomodulatory effects of Salvianolic acid B in a spontaneous abortion mouse model. Journal of Reproductive Immunology. $2020 \mathrm{Feb}$ 1;137:103075.

30. Litonjua AA, Weiss ST. Is vitamin D deficiency to blame for the asthma epidemic?. Journal of Allergy and Clinical Immunology. 2007 Nov 1;120(5):1031-5. 